\title{
BMJ Open How do delirium motor subtypes differ in phenomenology and contributory aetiology? a cross-sectional, multisite study of liaison psychiatry and palliative care patients
}

Kevin Glynn (10 , ${ }^{1}$ Frank McKenna, ${ }^{1}$ Kevin Lally, ${ }^{1}$ Muireann O’Donnell, ${ }^{1}$ Sandeep Grover, ${ }^{2}$ Subho Chakrabarti, ${ }^{2}$ Ajit Avasthi, ${ }^{2}$ Surendra K Mattoo, ${ }^{2}$ Akhilesh Sharma, ${ }^{2}$ Abhishek Ghosh, ${ }^{2}$ Ruchita Shah, ${ }^{2}$ David Hickey, ${ }^{1}$ James Fitzgerald, ${ }^{3,4}$ Brid Davis, ${ }^{5}$ Niamh O'Regan, ${ }^{6}$ Dimitrious Adamis, ${ }^{7}$ Olugbenja Williams, ${ }^{1}$ Fahad Awan, ${ }^{1} \mathrm{C}$ Dunne (D) , ${ }^{5}$ Walter Cullen, ${ }^{8}$ Shane Mclnerney, ${ }^{9}$ John McFarland, ${ }^{10}$ Faiza Jabbar, ${ }^{9}$ Henry O'Connell, ${ }^{11}$ Paula T Trzepacz, ${ }^{12,13}$ Maeve Leonard, ${ }^{1}$ David Meagher ${ }^{1,5}$

To cite: Glynn K, McKenna F, Lally $\mathrm{K}$, et al. How do delirium motor subtypes differ in phenomenology and contributory aetiology? a crosssectional, multisite study of liaison psychiatry and palliative care patients. BMJ Open 2021;11:e041214. doi:10.1136/ bmjopen-2020-041214

- Prepublication history for this paper is available online. To view these files, please visit the journal online (http://dx.doi org/10.1136/bmjopen-2020041214).

Received 17 July 2020 Revised 15 March 2021 Accepted 26 March 2021

Check for updates

(C) Author(s) (or their employer(s)) 2021. Re-use permitted under CC BY-NC. No commercial re-use. See rights and permissions. Published by BMJ.

For numbered affiliations see end of article.

Correspondence to

Dr Kevin Glynn;

glynnkevin@hotmail.com

\section{ABSTRACT}

Objectives To investigate whether delirium motor subtypes differ in terms of phenomenology and contributory aetiology.

Design Cross-sectional study.

Setting International study incorporating data from Ireland and India across palliative care, old age liaison psychiatry and general adult liaison psychiatry settings.

Participants 1757 patients diagnosed with delirium using criteria from the Diagnostic and Statistical Manual of Mental Disorders, Fourth edition (DSM IV).

\section{Primary and secondary outcome}

measures Hyperactive, mixed and hypoactive delirium subtypes were identified using the abbreviated version of the Delirium Motor Subtype Scale. Phenomenology was assessed using the Delirium Rating Scale Revised. Contributory aetiologies were assessed using the Delirium Aetiology Checklist (DEC), with a score $>2$ indicating that the aetiology was likely or definitely contributory.

Results Hypoactive delirium was associated with dementia, cerebrovascular and systemic infection aetiologies $(p<0.001)$ and had a lower overall burden of delirium symptoms than the other motor subtypes. Hyperactive delirium was associated with younger age, drug withdrawal and the DEC category other systemic aetiologies $(p<0.001)$. Mixed delirium showed the greatest symptom burden and was more often associated with drug intoxication and metabolic disturbance $(p<0.001)$. All three delirium motor subtypes had similar levels of impairment in attention and visuospatial functioning but differed significantly when compared with no subtype $(p<0.001)$. Conclusions This study indicates a pattern of aetiology and symptomatology of delirium motor subtypes across a large international sample that had previously been lacking. It serves to improve our understanding of this complex condition and has implications in terms of early detection and management of delirium.

\section{Strengths and limitations of this study}

This study comprised an international database with a large sample size.

- Patients from palliative care, old age liaison psychiatry and general adult liaison psychiatry populations were included.

- Instruments used to determine delirium motor subtypes and symptomatology have been widely validated across different populations and clinical settings.

- Limitations include the fact that this study provides a broad overview in terms of contributory aetiologies and further research is needed to investigate more specific aetiological findings.

\section{INTRODUCTION}

Delirium is a common neuropsychiatric condition that is independently associated with significantly increased morbidity and mortality. ${ }^{1}$ It is viewed as a unitary cognitive syndrome that is characterised by a heterogenous neuropsychiatric presentation and fluctuating course. ${ }^{2}$ Despite its importance in terms of prognosis, it often goes undiagnosed or undetected in busy clinical settings. ${ }^{3}$ This represents a significant issue in terms of patient care, particularly since delirium frequently represents a reversible condition and therefore its early detection and management is vital.

The different motor presentations of delirium are an important factor in complicating its diagnosis and treatment and have become the focus of efforts to improve our 
understanding of this complex condition. Lipowski ${ }^{4}$ developed the concept of delirium motor subtypes in the modern era whereby he proposed two main subtypes of delirium, hypoactive and hyperactive, and later added a third distinct mixed category. ${ }^{5}$ This was expanded on by Liptzin and Levkoff, ${ }^{6}$ who added an operationalised definition of subtypes. While issues with criteria and definitions used initially led to a lack of consistency in diagnosis between studies, ${ }^{7-9}$ focusing on purely motor rather than neuropsychiatric symptoms has emerged as the most established method of categorisation of subtypes. ${ }^{1011}$ This is supported by studies that have demonstrated that these subtypes can be distinguished bioelectronically by using motion analysis, can be identified as distinct categories using latent class analysis and are generally stable over time. ${ }^{12-14}$

Studies have demonstrated that delirium motor subtypes differ in terms of their symptomatology, severity and outcomes. ${ }^{10-14}$ Hypoactive delirium has been associated with increased risk of mortality. ${ }^{15-18}$ However, it is unclear to what extent this is confounded by the relationship between hypoactive presentation and factors such as burden of comorbidity and medication exposure since many of these studies have taken place in a palliative care setting. In addition, patients with hypoactive presentations are typically detected later and frequently misdiagnosed as depression, with important implications for patient management and prognosis. ${ }^{19}$ In contrast, patients with hyperactive or mixed delirium are more likely to receive antipsychotic medications and their delirium is more likely to be reversible. ${ }^{20}$ It is therefore important that delirium motor subtypes are accurately recognised in clinical practice.

Understanding symptomatology of delirium motor subtypes can help aid in their recognition. Studies to date have generally indicated that hyperactive delirium tends to present more often with symptoms of perceptual disturbance, delusions, lability of affect and motor agitation $^{21}$ and that thought process abnormalities and motor retardation are more associated with the hypoactive subtype. ${ }^{22}$ Some research has shown that mixed subtype is most severe in terms of having a greater burden of symptomatology with high levels of perceptual disturbance, delusions, lability of affect and both motor agitation and motor retardation. ${ }^{22}$ Cognitive impairment is generally similar across subtypes but findings have varied. ${ }^{23}$ However, thus far studies have been hampered by being confined to a particular clinical setting with a paucity of large-scale research to confirm their findings.

Another key question is whether delirium motor subtypes differ in terms of their causation. Delirium reflects the interaction between a variety of predisposing factors (eg, age, pre-existing Central nervous system (CNS) pathology) with precipitating insults (eg, physical illness, medication exposure, medical interventions) that result in the emergence of syndromal delirium. The aetiological underpinnings of delirium are thus complex and multifaceted, with typically three to four contributory aetiologies per episode. ${ }^{20}$ Identifying contributory aetiologies to different delirium motor subtypes is important, as the primary treatment of delirium involves treating its underlying causes. Identifying underlying causes may also help in the prevention of delirium, with a knock-on effect in terms of patient morbidity and mortality.

Despite its importance, the relationship between different contributory aetiologies and delirium motor subtype remains unclear. Some evidence indicates that certain aetiologies such as metabolic factors or organ failure are more common in hypoactive delirium, with substance intoxication and withdrawal more typically associated with the hyperactive subtype. ${ }^{24-27}$ However, other studies have failed to replicate these findings ${ }^{20} 28$ and a suitably designed study (eg, sufficiently powered) to explore the relationship between the many different categories of aetiology and delirium subtype profile has been lacking.

The aim of the current study is to compare delirium motor subtypes in terms of aetiology, phenomenology and symptom severity using a large international database derived from studies conducted across a variety of different clinical populations and settings.

\section{METHODS}

\section{Patient and public involvement}

No patient involvement.

\section{Subjects and design}

This study used a combined data set of existing related databases from two countries, Ireland ${ }^{202-34}$ and India. ${ }^{35-43}$ All research took place between 2008 and 2020 inclusive. Raters for data included in this study were trained by an expert with over 20 years' experience in the field of delirium research (DM), through training workshops in both Ireland and India using well validated assessment methods for these clinical populations as outlined below.

Research was conducted across three clinical settings: palliative care, old age liaison psychiatry and general adult liaison psychiatry.

\section{Palliative care}

This group consisted of consecutive referrals to a liaison psychiatry service in a hospice setting that were subsequently diagnosed as having delirium at the time of assessment. Research took place at Milford Hospice in Limerick, Ireland. ${ }^{30-33}$

\section{Old age CL psychiatry}

This group consisted of consecutive referrals to old age Community Liaison (CL) psychiatry services in two Irish Hospitals; University Hospital Limerick and University Hospital Galway, who were diagnosed with delirium at the time of assessment. ${ }^{20} 3334$

\section{General adult CL psychiatry}

This group consisted of consecutive referrals to a general adult CL psychiatry service at the Post Graduate Institute 
for Medical Research in Chandigarh, India, who were diagnosed with delirium at the time of assessment. ${ }^{35-43}$

\section{Assessment}

\section{Delirium diagnosis}

Delirium was diagnosed by the psychiatric teams according to Diagnostic and Statistical Manual of Mental Disordersfourth edition (DSM IV) ${ }^{44}$ criteria using all available clinical information including patient assessment and collateral information from nursing staff, family and the patient's medical records.

\section{Dementia diagnosis}

Dementia status was determined according to (1) a preexisting diagnosis, or (2) on the basis of detailed history and examination taking in aspects such as the patient's functional ability, neuroimaging and cognitive decline prior to assessment and was made in accordance with DSM IV. Cognitive decline prior to assessment was assessed using the Short Form of the Informant Questionnaire on Cognitive Decline in the Elderly (Short IQCODE), ${ }^{45}$ which was administered to the patient's next of kin or main carer.

The IQCODE comprises a 16-item informant questionnaire comparing the individual's ability on day-to-day items with their performance 10 years ago. Items are scored by the rater from $1=$ much improved, $3=$ unchanged to $5=$ much worse. Items include aspects of daily life such as the ability to remember conversations that happened the previous day, address and telephone numbers and where things are kept. Scores are added up and divided by the total number of questions $(n=16)$. The resultant score ranges from 1 to 5 . All databases in this analysis that used the IQCODE score to aid in dementia diagnosis used a cut-off of $\geq 3.5$ to signify likely dementia. This was then combined with all relevant clinical information to make a diagnosis.

\section{Delirium motor subtypes}

Delirium motor subtypes were differentiated using the abbreviated version of the Delirium Motor Subtype Scale (DMSS-4). ${ }^{11}$ The DMSS-4 was developed from the longer, 13-item, Delirium Motor Subtype Scale (DMSS) ${ }^{46}$ using latent class analysis to show the four symptoms that best differentiated the subtypes from the original DMSS. ${ }^{11}$ It comprises two items denoting hyperactivity (increased activity and loss of control of activity) and two items denoting hypoactivity (decreased speed of actions and decreased amount of speech), with mixed subtype defined as the presence of both hyperactive and hypoactive criteria over the previous 24-hour period. No subtype describes a presentation in which neither the criteria for hyperactive nor hypoactive delirium are fulfilled. The DMSS-4 was developed for quick and accurate identification of delirium motor subtype in busy clinical practice and has shown a good concordance with the original DMSS and has been widely validated across a variety of populations and clinical settings. ${ }^{1129} 303435$

\section{Aetiology}

Contributory aetiologies were identified using the Delirium Aetiology Checklist (DEC). ${ }^{47}$ The DEC is a 13-item checklist that is designed to document the aetiological underpinnings contributing to a delirium episode. Its 13 categories are: drug intoxication, drug withdrawal, metabolic/endocrine disturbance, traumatic brain injury, seizures, infection (intracranial), infection (systemic), neoplasm (intracranial), neoplasm (systemic), cerebrovascular, organ insufficiency, other CNS and other systemic. Other CNS includes neurological conditions such as Parkinson's disease and multiple sclerosis while other systemic includes conditions such as postoperative state, immunosuppression or heat stroke. These categories are present to allow the rater to list contributory aetiologies that do not fit under the other 11 items.

Each aetiology is rated on a scale according to its likelihood of being contributory to the delirium. This scale ranges from $0=$ ruled out/not present/not relevant to $4=$ definite cause. Raters can therefore document multiple aetiologies and their level of contribution to a particular episode of delirium. For the purposes of this study, DEC items were broken down into two categories: unremarkable (score 0-2) and possibly/probably contributory (scores of 3 or 4). This also allowed for the total and mean number of likely contributory aetiologies to be calculated and compared between delirium motor subtypes.

\section{Delirium symptomatology and severity}

Delirium severity and symptomatology were measured using the Delirium Rating Scale Revised-98 (DRS R98). ${ }^{48}$ The DRS-R98 is a 16 -item clinician rated scale used to rate the severity of delirium both overall and on a broad range of neuropsychiatric and cognitive symptoms. It is made up of 13 severity items and 3 diagnostic items. Each item is rated 0 (absent/normal) to 3 (severe impairment), with descriptors attached to each severity level. The severity scale (items 1-13) range from a score or 0-39 with larger scores indicating more severe delirium. A score of over 15 points typically indicates delirium and 18 points indicates delirium when dementia is present. The DRS-R98 can be divided into non-cognitive (items 1-8) and cognitive (9-13) subscales based on construct validity. It has been validated across clinical settings and has been shown to have a high inter-rater reliability, sensitivity and specificity at detecting delirium. It has also been used to determine differing symptomatology and severity across delirium motor subtypes. ${ }^{10} 12$

\section{Statistical analysis}

Patients with missing data for any of the variables being examined were excluded from our final analysis. Continuous normally distributed variables are reported as means and SD, while categorical variables are reported as counts and percentages. Normally distributed data were compared using Analysis of variance (ANOVA), whereas non-parametric and categorical data were compared using Kruskal-Wallis and $\mathrm{X}^{2}$ tests, respectively. 
Table 1 Demographic and clinical data for overall population and subpopulations

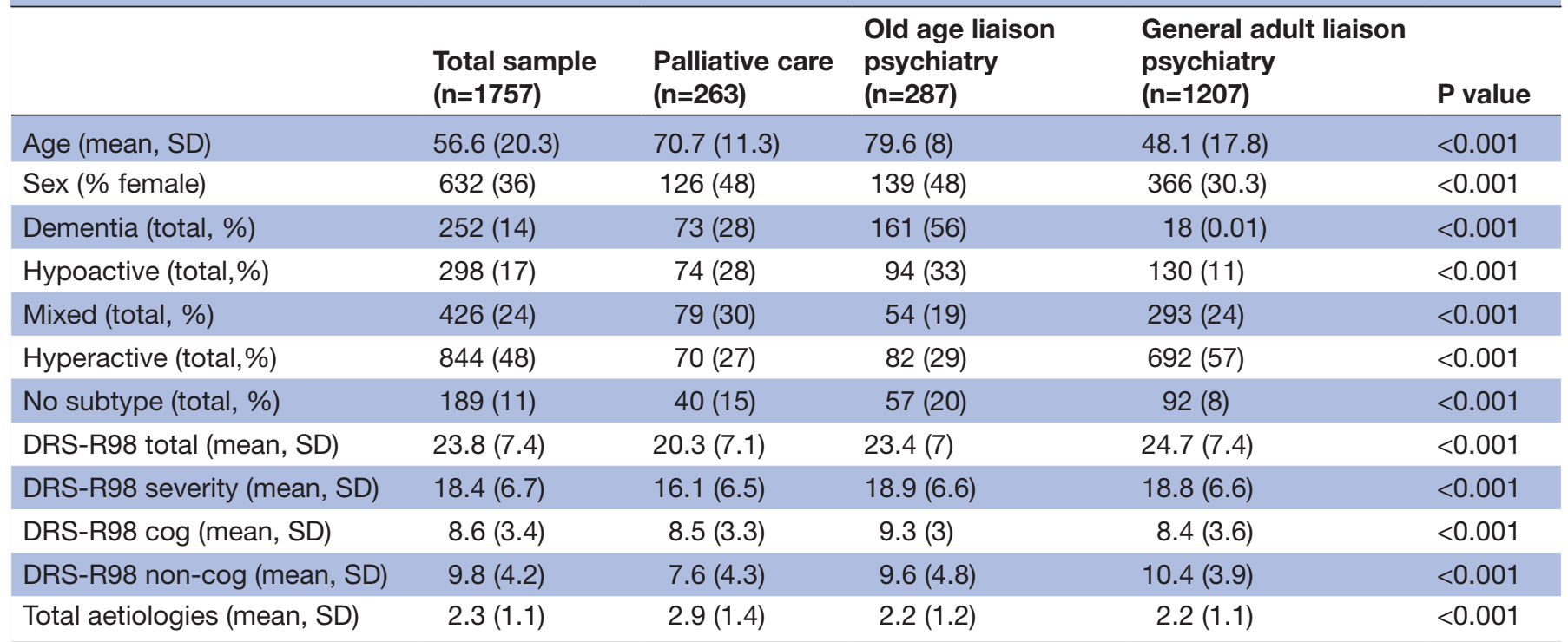

DRS R98, Delirium Rating Scale Revised; DRS R98 Cog, Delirium Rating Scale Revised Cognition score (items 9-13); DRS R98 non-cog, Delirium Rating Scale Revised non-cognitive (items 1-8); hyperactive, hyperactive delirium; hypoactive, hypoactive delirium; mixed, mixed delirium; no subtype, no delirium motor subtype.

Standardised adjusted residuals were used for post-hoc analysis of $\mathrm{X}^{2}$ tests, with a level of greater than $1.96(2.0$ is used by convention) used to indicate statistical significance. ${ }^{49}$ Dunn multiple comparison test was used for post-hoc analysis of the Kruskal-Wallis test, while the Bonferroni procedure was used during post-hoc analysis for ANOVA. Statistical analysis was conducted using the SPSS V.25 package.

\section{RESULTS}

\section{Patient demographics and dementia status}

The total number of subjects after excluding missing data $(n=176)$ was 1757 . They comprised $1124(64 \%)$ men and $633(36 \%)$ women. This included 263 patients from palliative care, 287 from old age liaison psychiatry and 1207 from general adult liaison psychiatry. Dementia status was listed in 1685 (98\%) cases and marked as unknown or not listed in 72 cases. The number of patients diagnosed with comorbid dementia was $252(15 \%)$. A breakdown of the data sets used is outlined in table 1 .

As can be seen from table 1, significant differences exist across the databases on all parameters analysed. Old age liaison psychiatry were the oldest group and had the greatest proportion of patients with comorbid dementia, while general adult liaison psychiatry were the youngest and had the highest overall scores on the DRS-R98. The palliative care group had a significantly greater number of contributory aetiologies than the other groups.

Table 2 Demographic information and clinical setting of delirium motor subtypes

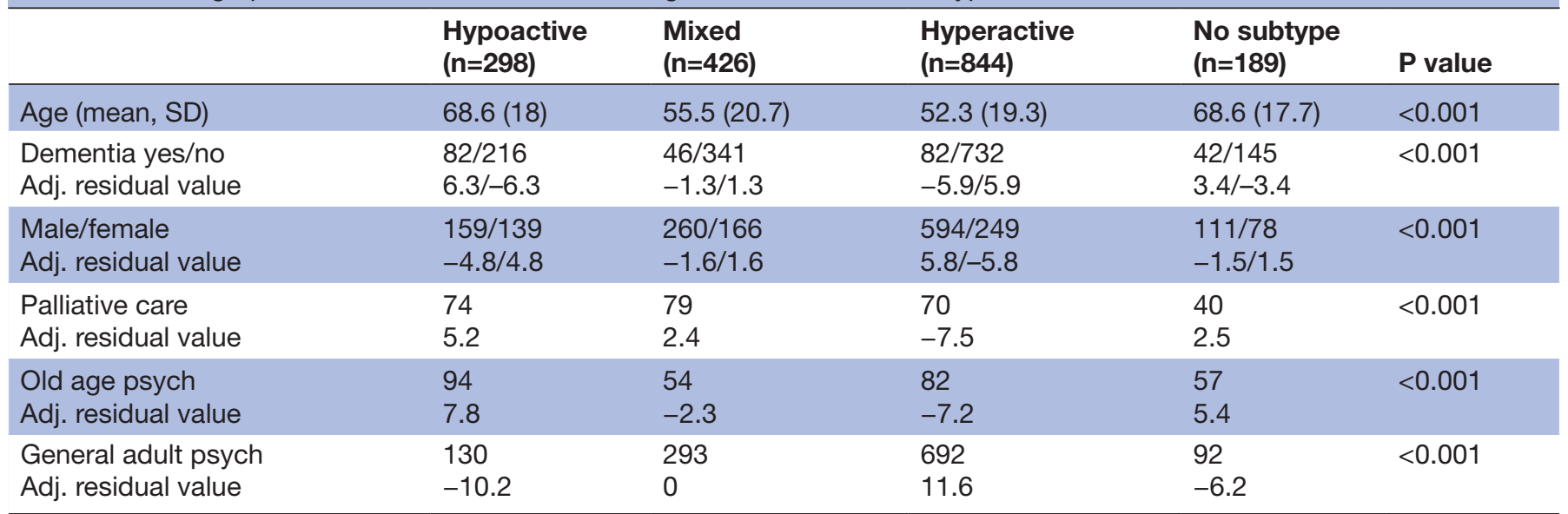

$P$ value is significant at $<0.01$.

Adj. residual value, adjusted residual value; hyperactive, hyperactive delirium; hypoactive, hypoactive delirium; mixed, mixed delirium. 
Table 2 indicates that there were significant differences in mean age between the delirium motor subtypes, with hyperactive significantly younger and hypoactive significantly older.

Hypoactive and no subtype were significantly associated with positive dementia status, female gender and palliative care and old age liaison psychiatry settings. In contrast, hyperactive delirium was significantly associated with negative dementia status, male gender and had a greater proportion of cases in general adult liaison psychiatry setting. Mixed delirium did not show any relationship to either gender or dementia status but was significantly associated with the palliative care group.

\section{Aetiology of delirium motor subtypes}

Metabolic disturbance was the most common contributory aetiology and was present in $782(44 \%)$ of the total sample, followed by systemic infection in $493(28 \%)$ and organ sufficiency which was listed in 336 (19\%) of cases (see table 2). The mean number of aetiological factors per case was 2.11 (1.33) with more than one documented probable aetiology evident in $80 \%$ of cases $(n=1409)$.

The mean and SD number of aetiologies in the different delirium motor subtypes were as follows: no subtype 1.16 (1.34), hypoactive 2.46 (1.2), mixed 2.46 (1.2) and hyperactive 2.3 (1.67). No subtype had significantly lower active aetiologies attributed per case.

As seen in table 3 , hypoactive delirium was significantly associated with systemic infection, intracranial neoplasm and cerebrovascular aetiologies. Mixed delirium was significantly associated with drug intoxication and metabolic disturbance and hyperactive delirium was significantly associated with drug withdrawal and other systemic aetiologies. No subtype did not show any significant associations in terms of aetiologies.

\section{Symptomatology of delirium motor subtypes}

Significant differences between delirium motor subtypes were found for all items on the DRS-R98 scale (see table 4). Patients with hyperactive delirium scored higher

Table 3 Relationship between delirium motor subtypes and aetiologies as listed on the Delirium Aetiology Checklist

\begin{tabular}{|c|c|c|c|c|c|c|c|}
\hline & $\begin{array}{l}\text { Total } \\
(\mathrm{n}=1757)^{\star}\end{array}$ & $\begin{array}{l}\text { Hypoactive } \\
(\mathrm{n}=298)\end{array}$ & $\begin{array}{l}\text { Mixed } \\
(n=426)\end{array}$ & $\begin{array}{l}\text { Hyperactive } \\
(\mathrm{n}=844)\end{array}$ & $\begin{array}{l}\text { No subtype } \\
(n=189)\end{array}$ & $\mathrm{x}^{2}$ & $P$ value \\
\hline $\begin{array}{l}\text { 1. Drug Intoxication } \\
\text { Adj. residual value }\end{array}$ & 84 & $\begin{array}{l}17 \\
0.7\end{array}$ & $\begin{array}{l}31 \\
2.8\end{array}$ & $\begin{array}{l}28 \\
-2.7\end{array}$ & $\begin{array}{l}8 \\
-0.4\end{array}$ & 10.4 & $<0.001$ \\
\hline $\begin{array}{l}\text { 2. Drug withdrawal } \\
\text { Adj. residual value }\end{array}$ & 125 & $\begin{array}{l}9 \\
-3.2\end{array}$ & $\begin{array}{l}29 \\
-0.2\end{array}$ & $\begin{array}{l}77 \\
3.3\end{array}$ & $\begin{array}{l}10 \\
-1.1\end{array}$ & 15 & $<0.001$ \\
\hline $\begin{array}{l}\text { 3. Met disturbance } \\
\text { Adj. residual value }\end{array}$ & 782 & $\begin{array}{l}120 \\
-2.2\end{array}$ & $\begin{array}{l}209 \\
2.4\end{array}$ & $\begin{array}{l}391 \\
1.9\end{array}$ & $\begin{array}{l}62 \\
-3.7\end{array}$ & 22.3 & $<0.001$ \\
\hline $\begin{array}{l}\text { 4. Traumatic brain injury } \\
\text { Adj. residual value }\end{array}$ & 72 & $\begin{array}{l}6 \\
-2.1\end{array}$ & $\begin{array}{l}25 \\
2.2\end{array}$ & $\begin{array}{l}37 \\
0.7\end{array}$ & $\begin{array}{l}4 \\
-1.5\end{array}$ & 9.5 & 0.02 \\
\hline $\begin{array}{l}\text { 5. Seizure } \\
\text { Adj. residual value }\end{array}$ & 87 & $\begin{array}{l}19 \\
1.1\end{array}$ & $\begin{array}{l}20 \\
-0.2\end{array}$ & $\begin{array}{l}40 \\
-0.3\end{array}$ & $\begin{array}{l}8 \\
-0.6\end{array}$ & 1.3 & 0.72 \\
\hline $\begin{array}{l}\text { 6. Intracranial infection } \\
\text { Adj. residual value }\end{array}$ & 75 & $\begin{array}{l}16 \\
0.9\end{array}$ & $\begin{array}{l}21 \\
0.8\end{array}$ & $\begin{array}{l}33 \\
-0.6\end{array}$ & $\begin{array}{l}5 \\
-1.2\end{array}$ & 2.7 & 0.44 \\
\hline $\begin{array}{l}\text { 8. Intracranial neoplasm } \\
\text { Adj. residual value }\end{array}$ & 65 & $\begin{array}{l}19 \\
2.5\end{array}$ & $\begin{array}{l}19 \\
1\end{array}$ & $\begin{array}{l}26 \\
-1.2\end{array}$ & $\begin{array}{l}1 \\
-2.5\end{array}$ & 12.3 & . $<0.001$ \\
\hline $\begin{array}{l}\text { 9. Systemic neoplasm } \\
\text { Adj. residual value }\end{array}$ & 173 & $\begin{array}{l}20 \\
-2.2\end{array}$ & $\begin{array}{l}37 \\
0.9\end{array}$ & $\begin{array}{l}101 \\
3\end{array}$ & $\begin{array}{l}15 \\
-1\end{array}$ & 10.3 & 0.02 \\
\hline $\begin{array}{l}\text { 10. Cerebrovascular } \\
\text { Adj. residual value }\end{array}$ & 98 & $\begin{array}{l}31 \\
3.8\end{array}$ & $\begin{array}{l}19 \\
-1.1\end{array}$ & $\begin{array}{l}39 \\
-1.6\end{array}$ & $\begin{array}{l}9 \\
-0.6\end{array}$ & 14.2 & $<0.001$ \\
\hline $\begin{array}{l}\text { 11. Organ insufficiency } \\
\text { Adj. residual value }\end{array}$ & 336 & $\begin{array}{l}54 \\
-0.8\end{array}$ & $\begin{array}{l}87 \\
0.9\end{array}$ & $\begin{array}{l}161 \\
0.2\end{array}$ & $\begin{array}{l}34 \\
-0.6\end{array}$ & 1.5 & 0.69 \\
\hline $\begin{array}{l}\text { 12. CNS other } \\
\text { Adj. residual value }\end{array}$ & 57 & $\begin{array}{l}11 \\
0.4\end{array}$ & $\begin{array}{l}11 \\
0.8\end{array}$ & $\begin{array}{l}28 \\
3\end{array}$ & $\begin{array}{l}7 \\
0.3\end{array}$ & 0.7 & 0.86 \\
\hline
\end{tabular}

$P$ value is significant at $<0.01$.

*Total patients: note that several aetiologies can be listed for each patient.

Adj. residual value, adjusted residual value (this needs to explicitly stated somewhere-as to what does this mean); hypoactive, hypoactive delirium; mixed, mixed delirium. 


\begin{tabular}{|c|c|c|c|c|c|c|c|}
\hline DRS items (mean, SD) & $\begin{array}{l}\text { Hypoactive } \\
\text { I }\end{array}$ & $\begin{array}{l}\text { Mixed } \\
\text { II }\end{array}$ & $\begin{array}{l}\text { Hyperactive } \\
\text { III }\end{array}$ & $\begin{array}{l}\text { No subtype } \\
\text { IV }\end{array}$ & $x^{2}$ & $P$ value & $\begin{array}{l}\text { Post-hoc } \\
\text { significant pairs* }\end{array}$ \\
\hline 1. Sleep disturbance & $1.72(0.8)$ & $2.17(0.7)$ & $2.21(0.78)$ & $1.53(0.9)$ & 166.5 & $<0.001$ & III>I, II>I, IV<II, III \\
\hline 2. Perceptual disturbance & $0.71(1.1)$ & $1.30(1.2)$ & $1.4(1.2)$ & $0.7(1.1)$ & 135.2 & $<0.001$ & III $>$ I, II >I, IV $<1 \mathrm{I}, \mathrm{III}$ \\
\hline 3. Delusions & $0.43(0.8)$ & $0.64(0.9)$ & $0.57(0.9)$ & $0.26(0.6)$ & 48.3 & $<0.001$ & III $>$ I, II>I, IV< II, III \\
\hline 4. Lability of affect & $0.91(0.8)$ & $1.26(0.9)$ & $1.24(0.9)$ & $0.57(0.7)$ & 125.7 & $<0.001$ & III >I, II>I, IV<I, II, III \\
\hline 5. Language & $0.90(0.9)$ & $1.22(0.9)$ & $1.27(1)$ & $0.71(0.8)$ & 90.3 & $<0.001$ & III>I, II>I, IV<II, III \\
\hline 6. Thought process & $1.34(1.8)$ & $1.31(0.9)$ & $1.37(1)$ & $1(0.83)$ & 20.9 & $<0.001$ & IV $<$ I, II, III \\
\hline 7. Motor agitation & $0.83(0.9)$ & $1.63(0.9)$ & $2.1(1.1)$ & $0.92(1)$ & 447.8 & $<0.001$ & $|I|>||>|| I,|>|,|I V<| I,|I|$ \\
\hline 8. Motor retardation & $1.29(0.9)$ & $1.27(1)$ & $0.29(0.7)$ & $0.52(0.8)$ & 509.4 & $<0.001$ & I $>$ III, II $>$ III, IV $<$ I, II, III \\
\hline 9. Orientation & $1.53(0.9)$ & $1.92(0.8)$ & $2(0.8)$ & $1.3(1.1)$ & 144.7 & $<0.001$ & III $>$ II>I, IV<II, III \\
\hline 10. Attention & $1.98(0.9)$ & $2.21(0.8)$ & $2.1(0.8)$ & $1.7(1)$ & 53.5 & $<0.001$ & IV<I, II, III \\
\hline 11. Short-term memory & $1.68(0.9)$ & $1.82(0.9)$ & $1.85(1)$ & $1.55(1)$ & 20.3 & $<0.001$ & III>I, IV<II, III \\
\hline 12. Long-term memory & $1.12(1)$ & $1.31(1)$ & $1.24(1.1)$ & $0.8(0.9)$ & 43.5 & $<0.001$ & II $>$ I, IV $<$ I, II, III \\
\hline 13. Visuospatial ability & $1.47(1)$ & $1.64(1.1)$ & $1.56(1.1)$ & $1.15(1.1)$ & 31.4 & $<0.001$ & IV $<$ I, II, III \\
\hline 14. Temporal onset & $1.82(0.9)$ & $2.1(0.7)$ & $2.3(1)$ & $1.74(1)$ & 94 & $<0.001$ & III $>$ II $>$ I, III $>$ I, IV $<$ II, III \\
\hline 15. Fluctuation & $0.97(0.6)$ & $1.41(0.6)$ & $1.65(0.8)$ & $0.80(0.8)$ & 272 & $<0.001$ & $\|I I>\|>1,\|>|| I V<\| I,, I I \mid$ \\
\hline 16. Physical disorder & $1.66(0.4)$ & $1.82(0.4)$ & $1.87(0.4)$ & $1.67(0.5)$ & 82.1 & $<0.001$ & III>I, II>I, IV<II, III \\
\hline Non-cognitive (i1-8) & $8.12(4.1)$ & $10.8(3.6)$ & $10.4(4.1)$ & $6.22(3.6)$ & 275.8 & $<0.001$ & III>I, II>I, IV<I, II, III \\
\hline Cognitive (9-13) & $7.76(3.2)$ & $8.88(3.4)$ & $8.44(3.5)$ & $6.45(3.3)$ & 101.7 & $<0.001$ & III >I, II>I, IV $<$ I, II, III \\
\hline Severity (1-13) & $15.81(6.1)$ & $19.67(5.9)$ & $19.26(6.8)$ & $12.62(5.6)$ & 38.9 & $<0.001$ & $\| I I<I I>I, I V<I, I I, I I I$ \\
\hline DRS-R98 total (1-16) & $20.30(6.9)$ & $25(6.4)$ & $25.1(7.6)$ & $16.95(6.7)$ & 259.4 & $<0.001$ & $\| \mathrm{II}>\mathrm{I}, \mathrm{II}>\mathrm{I}, \mathrm{IV}<\mathrm{l}, \mathrm{II}, \mathrm{II}$ \\
\hline
\end{tabular}

*Only significant differences at the level of $p<0.01$ are shown.

DRS, Delirium Rating Scale; DRS-R98, DRS Revised; hyperactive, hyperactive delirium; hypoactive, hypoactive delirium; mixed, mixed delirium.;

on severity of symptoms than those with hypoactive delirium and no subtype across most items, excluding motor retardation. However, severity of symptoms were not significantly different between hyperactive and mixed subtypes across several items (only statistically significant differences between pairwise comparisons are shown). Patients with mixed subtype had significantly greater total severity score than both hypoactive and hyperactive subtypes. As expected, patients with hypoactive delirium showed significantly greater severity of motor retardation (item 8) than hyperactive delirium and the opposite pattern was true for motor agitation (item 7 ).

In terms of cognition, hypoactive, mixed and hyperactive subtypes score significantly higher than no subtype on totals for cognitive scores (items 9-13). All subtypes (hypoactive, mixed, hyperactive) scored significantly greater in terms of impairment on visuospatial ability (item 13) and attention (item 10) than the no subtype group.

\section{DISCUSSION}

This analysis of a large international sample across multiple clinical settings (palliative care, old age liaison and general adult liaison psychiatry referrals) identified that delirium motor subtypes differ in respect of aetiology, neuropsychiatric symptom severity and demographic factors such as age and gender. This work emphasises the typically multifactorial nature of delirium causation, whereby there are typically two to three active aetiological factors in any case and where single aetiology delirium is the exception. These observations further enhance understanding of this complicated condition with implications for delirium recognition and management.

There was a significant difference between delirium motor subtypes in age, dementia status and gender. Patients with hypoactive delirium were more likely to be of older age, women and have comorbid dementia compared with those with hyperactive presentations. They were also more common in old age liaison psychiatry and palliative care settings. While previous research has found that hypoactive delirium tends to be more common in older patients, ${ }^{89}$ this is the first time such an association has been documented in a large sample incorporating different clinical settings. This is important, as hypoactive delirium is associated with greater mortality and is often missed or misdiagnosed, particularly in older patients. ${ }^{19}$

Despite its association with an increased risk of mortality in previous research, hypoactive delirium was rated as 
having a lower overall burden of delirium symptoms on the DRS-R98 than mixed or hyperactive subtypes in the current study. One possible explanation for this finding is that those with hyperactive delirium are younger, more physically able and are more likely to come to the attention of staff and are more florid in terms of neuropsychiatric symptoms such as delusions and hallucinations. This notion is supported by previous research, which has shown that those with hyperactive delirium were more likely to receive antipsychotic medication. ${ }^{22}$ Mixed delirium had the greatest severity scores and burden of symptomatology which is a likely reflection of the fact that they include diagnostic criteria for both hypoactive and hyperactive subtypes. This is consistent with previous findings in the area. ${ }^{9}$

Delirium symptoms can be divided into neuropsychiatric (involving sleep, motor behaviour and psychosis) and cognitive. Of note, the three motor subtypes differed in terms of the former but had similar levels of disturbance in respect of attention and visuospatial function which are key neuropsychological domains in delirium. This is in keeping with previous findings that suggest that delirium subtypes have a consistent cognitive profile but differ in respect of other non-cognitive symptoms, emphasising that it is a cognitive disorder with disturbances to attention and visuospatial function representing core elements. This supports the use of tests of attention and visuospatial ability for reliable and consistent detection of delirium, including all of its presentations. In addition, the majority of patients with full syndromal delirium have evidence of discernible alterations in motor behaviour such that those with no motor subtype differed in respect of overall delirium symptom severity (including less severe cognitive disturbance), suggesting that many of these patients have mild or subsyndromal illness.

While attributing aetiologies to particular delirium subtypes is challenging due to the multifactorial nature of the condition, the current study aimed to give an overview of likely contributory aetiologies by breaking them down into 13 categories using the DEC. Hypoactive delirium was significantly associated with systemic infection, intracranial neoplasm and cerebrovascular aetiologies when compared with other delirium motor subtypes. This is clinically important as delirium can be the principal presenting feature for a variety of acute medical emergencies such as sepsis and stroke. ${ }^{50}$ This study emphasises the need to maintain a high level of vigilance regarding the multifactorial nature of delirium causation as well as the possibility of silent background aetiologies.

This finding is in contrast to previous research, which has principally indicated an association between hypoactive delirium and metabolic factors and organ failure. ${ }^{25-28}$ One possible explanation for this discrepancy is that much of this previous research has taken place in palliative care settings and therefore may lead to a disproportionate representation of particular aetiologies (eg, organ failure, neoplasm). The current study overcomes this issue by including data from multiple clinical settings with a larger sample and is therefore more likely to give more accurate and generalisable results.

Of the contributory aetiologies identified, only drug withdrawal and other systemic causes were significantly associated with hyperactive subtype. Withdrawal from certain drugs, particularly alcohol, benzodiazepines and opiates are known to cause hyperactivity and agitation and our results confirm a well-established link between hyperactive delirium and drug withdrawal. The category of other systemic aetiologies includes postoperative states, the effects of radiation treatment or other rarer causes such as hypothermia. Future research is needed to clarify which of these other systemic causes is most associated with the hyperactive delirium subtype.

This study has several limitations. While the study is large and incorporates data from two countries, a mix of old age and adult liaison psychiatry referrals and palliative care assessments may not be a broad enough cross-section of patients to be truly generalisable. For example, delirium presentations in other setting such as ICU may differ in terms of aetiology and subtype. There was also a relatively high proportion of the sample that had no delirium motor subtype, despite being diagnosed with DSM IV delirium. This raises the question as to whether this group in fact had subsyndromal delirium and requires further investigation in future research. While the DEC has good face validity and has been used in much previous research, it has not been fully validated and it is unknown the degree to which it is affected by inter-rater reliability issue. It is also not an exhaustive list in terms of contributory aetiologies and only provides a broad overview of the likely contributory factors involved in the episode of delirium (eg, metabolic disturbance and drug intoxication are broad categories that each encompasses many causes of each). The cross-sectional study design may also not be ideal when studying a condition that fluctuates considerably and a longitudinal case design may provide better insights into how complex etiological underpinnings evolve over the course of an episode of delirium.

In conclusion, the current study indicates a pattern of aetiologies and symptomatology across delirium motor subtypes using a large combined international database. The association between hypoactive delirium, dementia, cerebrovascular disease and infection is an important insight for clinical practice, where these individuals may often be overlooked. Mixed delirium has the greatest symptom burden, combining both hypoactive and hyperactive features and is associated with drug intoxication and metabolic aetiologies. Those with hyperactive delirium are significantly younger, more likely to be men and more likely to be suffering the effects of drug withdrawal. This is, to the best of the authors knowledge, the first time such a large international database has been used to examine differences in delirium motor subtypes and it provides useful knowledge on this complex and often misdiagnosed condition. 


\section{Author affiliations}

${ }^{1}$ Department of Psychiatry, University Hospital Limerick, Limerick, Ireland ${ }^{2}$ Post Graduate Institute of Medical Education and Research, Chandigarh, India ${ }^{3}$ Department of Psychiatry, University of Cambridge School of Clinical Medicine, Cambridge, UK

${ }^{4}$ Cambridgeshire and Peterborough NHS Foundation Trust, Cambridge, UK

${ }^{5}$ Graduate Entry Medical School, University of Limerick, Limerick, Ireland

${ }^{6}$ Cork University Hospital Group, Cork, Ireland

${ }^{7}$ Sligo General Hospital, Sligo, Ireland

${ }^{8}$ School of Medicine, UCD, Dublin, Ireland

${ }^{9}$ University Hospital Galway, Galway, Ireland

${ }^{10}$ Clare Mental Health Services, Ennis General Hospital, Clare, Ireland

${ }^{11}$ University Hospital Limerick, Dooradoyle, Ireland

${ }^{12}$ Lilly Research Laboratories, Indianapolis, Indiana, USA

${ }^{13}$ Department of Psychiatry, Indiana University School of Medicine, Indianapolis, Indiana, USA

Correction notice This article has been corrected since it was first published. The name for the author 'Abhishek Ghosh' has been corrected.

Contributors KG, FM, KL, MO and DH combined the existing databases and KG wrote up the draft of the paper. DM was the principle investigator who oversaw the current project. JM, BD, NO, OW, FA, CD, WC, SM, JM, FJ, HO, PTT and ML were involved in data collection for the Irish part of the study and $D A$ was an advisor for statistical analysis. SC, SKM, AA, AS, AG and RS were involved in the design, data collection and analysis for the Indian part of the study while $S G$ was the principle investigator.

Funding Fees for publication were provided by University of Limerick, Ireland.

Competing interests None declared.

Patient and public involvement Patients and/or the public were not involved in the design, or conduct, or reporting, or dissemination plans of this research.

Patient consent for publication Not required.

Ethics approval Because of the non-invasive nature of the study, approval was given by the Limerick Regional Ethics Committee, Ireland (REC 100/12) to augment patient assent with proxy consent from next of kin (where possible) or a responsible caregiver for all participants in accordance with the Helsinki Guidelines for Medical Research involving human subjects. All of the Indian studies were approved by the Post Graduate Institute for Medical Research Ethics Review Committee (Int/ IEC/2015/659, Int/IEC/2017/690, Int/IEC/2015/229). Written consent was obtained from the primary caregivers of the patients and patients themselves wherever possible in accordance with the Helsinki Guidelines for Medical Research involving human subjects.

Provenance and peer review Not commissioned; externally peer reviewed.

Data availability statement № additional data are available.

Open access This is an open access article distributed in accordance with the Creative Commons Attribution Non Commercial (CC BY-NC 4.0) license, which permits others to distribute, remix, adapt, build upon this work non-commercially, and license their derivative works on different terms, provided the original work is properly cited, appropriate credit is given, any changes made indicated, and the use is non-commercial. See: http://creativecommons.org/licenses/by-nc/4.0/.

ORCID iDs

Kevin Glynn http://orcid.org/0000-0002-2103-9006

C Dunne http://orcid.org/0000-0002-5010-3185

\section{REFERENCES}

1 McCusker J, Cole M, Abrahamowicz M, et al. Delirium predicts 12-month mortality. Arch Intern Med 2002;162:457-63.

2 American Psychiatric Association. Diagnostic and statistical manual of mental disorders. 3rd edn. Washington, DC: American Psychiatric Association, 1982.

3 Meagher D, Leonard M. The active management of delirium: improving detection and treatment. Adv Psych Treat 2008;14:292-301.

4 Lipowski ZJ. Transient cognitive disorder in the elderly. Am J Psychiatry 1982;140:1426-36.

5 Lipowski ZJ. Delirium: acute confusional states. New York, NY: Oxford University Press, 1990.
6 Liptzin B, Levkoff SE. An empirical study of delirium subtypes. Br J Psychiatry 1992;161:843-5.

7 Albert MS, Levkoff SE, Reilly C, et al. The delirium symptom interview: an interview for the detection of delirium symptoms in hospitalized patients. J Geriatr Psychiatry Neurol 1992;5:14-21.

8 O'Keeffe ST, Lavan JN, O’Keeffe S. Clinical significance of delirium subtypes in older people. Age Ageing 1999;28:115-9.

9 Meagher D. Motor subtypes of delirium: past, present and future. Int Rev Psychiatry 2009;21:59-73.

10 Meagher DJ, Moran M, Raju B, et al. Motor symptoms in 100 patients with delirium versus control subjects: comparison of subtyping methods. Psychosomatics 2008;49:300-8.

11 Meagher D, Adamis D, Leonard M, et al. Development of an abbreviated version of the delirium motor subtyping scale (DMSS-4). Int. Psychogeriatr. 2014;26:693-702.

12 Meagher DJ, Leonard M, Donnelly S, et al. A longitudinal study of motor subtypes in delirium: frequency and stability during episodes. J Psychosom Res 2012;72:236-41.

13 Godfrey A, Leonard M, Donnelly S, et al. Validating a new clinical subtyping scheme for delirium with electronic motion analysis. Psychiatry Res 2010;178:186-90.

14 Koponen H, Hurri L, Stenbäck U, et al. Computed tomography findings in delirium. J Nerv Ment Dis 1989;177:226-31.

15 Jackson TA, Wilson D, Richardson S, et al. Predicting outcome in older hospital patients with delirium: a systematic literature review. Int J Geriatr Psychiatry 2016;31:392-9.

16 Yang FM, Marcantonio ER, Inouye SK, et al. Phenomenological subtypes of delirium in older persons: patterns, prevalence, and prognosis. Psychosomatics 2009;50:248-54.

17 Grover S, Ghormode D, Ghosh A, et al. Risk factors for delirium and inpatient mortality with delirium. J Postgrad Med 2013;59:263-70.

18 Gual N, Inzitari M, Carrizo G, et al. Delirium subtypes and associated characteristics in older patients with exacerbation of chronic conditions. Am J Geriatr Psychiatry 2018;26:1204-12.

19 Inouye SK, Foreman MD, Mion LC, et al. Nurses' recognition of delirium and its symptoms: comparison of nurse and researcher ratings. Arch Intern Med 2001;161:2467-73.

20 Meagher DJ, Leonard M, Donnelly S, et al. A longitudinal study of motor subtypes in delirium: relationship with other phenomenology, etiology, medication exposure and prognosis. J Psychosom Res 2011;71:395-403.

21 Grover S, Mattoo SK, Aarya KR, et al. Replication analysis for composition of the delirium motor subtype scale (DMSS) in a referral cohort from Northern India. Psychiatry Res 2013;206:68-74.

22 Meagher DJ, O'Hanlon D, O'Mahony E, et al. The use of environmental strategies and psychotropic medication in the management of delirium. Br J Psychiatry 1996;168:512-5.

23 Franco JG, Santesteban O, Trzepacz P. MMSE items that predict incident delirium and hypoactive subtype in older medical inpatients. Psychiatry Res 2020;2014:975-81.

24 Meagher DJ, O'Hanlon D, O'Mahony E, et al. Relationship between etiology and phenomenologic profile in delirium. J Geriatr Psychiatry Neurol 1998;11:146-9.

25 Morita T, Tei Y, Tsunoda J, et al. Underlying pathologies and their associations with clinical features in terminal delirium of cancer patients. J Pain Symptom Manage 2001;22:997-1006.

26 O'Keeffe ST, Lavan JN. Clinical significance of delirium subtypes in older people. Age Ageing 1999;28:115-9.

27 Gupta AK, Saravay SM, Trepacz PT. Delirium motoric subtypes. Psychosomatics 2005;46:158.

28 Sagawa R, Akechi T, Okuyama T, et al. Etiologies of delirium and their relationship to reversibility and motor subtype in cancer patients. Jpn J Clin Oncol 2009;39:175-82.

29 Meagher DJ, Leonard M, Donnelly S, et al. A comparison of neuropsychiatric and cognitive profiles in delirium, dementia, comorbid delirium-dementia and cognitively intact controls. J Neurol Neurosurg Psychiatry 2010;81:876-81.

30 Leonard M, Raju B, Conroy M, et al. Reversibility of delirium in terminally ill patients and predictors of mortality. Palliat Med 2008;22:848-54.

31 Davis $\mathrm{B}$. Towards improved recognitive and diagnosis of cognitive impairment and subsyndromal delirium: a cross sectional and longitudinal investigation. PhD thesis. University of Limerick, Ireland 2018.

32 Meagher DJ, O'Connell H, Leonard M, et al. Comparison of nove tools with traditional cognitive tests in detecting delirium in elderly medical patients. World J Psychiatry 2020;10:46-58.

33 Leonard M, Mclnerney S, McFarland J, et al. Comparison of cognitive and neuropsychiatric profiles in hospitalised elderly medical patients with delirium, dementia and comorbid delirium-dementia. BMJ Open 2016;6:e009212. 
34 Jabbar F, Leonard M, Meehan K, et al. Neuropsychiatric and cognitive profile of patients with DSM-IV delirium referred to an old age psychiatry consultation-liaison service. Int Psychogeriatr 2011;23:1167-74.

35 Grover S, Sharma A, Aggarwal M, et al. Comparison of symptoms of delirium across various motoric subtypes. Psychiatry Clin Neurosci 2014:68:283-91.

36 Grover S, Agarwal M, Sharma A, et al. Symptoms and aetiology of delirium: a comparison of elderly and adult patients. East Asian Arch Psychiatry 2013;23:56-64.

37 Grover S, Ghormode D, Ghosh A, et al. Risk factors for delirium and inpatient mortality with delirium. J Postgrad Med 2013;59:263-70.

38 Grover S, Mattoo SK, Aarya KR, et al. Replication analysis for composition of the delirium motor subtype scale (DMSS) in a referral cohort from Northern India. Psychiatry Res 2013;206:68-74.

39 Mattoo SK, Grover S, Chakravarty K, et al. Symptom profile and etiology of delirium in a referral population in northern India: factor analysis of the DRS-R98. J Neuropsychiatry Clin Neurosci 2012;24:95-101.

40 Grover S, Chakrabarti S, Shah R, et al. A factor analytic study of the delirium rating Scale-Revised-98 in untreated patients with delirium. J Psychosom Res 2011;70:473-8.

41 Grover S, Mahajan S, Chakrabarti S, et al. Comparative effectiveness of quetiapine and haloperidol in delirium: a single blind randomized controlled study. World J Psychiatry 2016;6:365-74.
42 Grover S, Sharma A, Kate N, et al. Symptom profile and outcome of delirium associated with alcohol withdrawal syndrome: a study from India. Am J Addict 2013;22:503-9.

43 Grover S, Kumar V, Chakrabarti S. Comparative efficacy study of haloperidol, olanzapine and risperidone in delirium. $J$ Psychosom Res 2011;71:277-81.

44 American Psychiatric Association. Diagnostic and statistical manual of mental disorders. 4th edn. Washington, DC: American Psychiatric Association, 2000.

45 Jorm AF. A short form of the informant questionnaire on cognitive decline in the elderly (IQCODE): development and cross-validation. Psychol Med 1994;24:145-53.

46 Meagher D, Moran M, Raju B, et al. A new data-based motor subtype schema for delirium. $J$ Neuropsychiatry Clin Neurosci 2008;20:185-93.

47 Trzepacz P, Meagher D. Neuropsychiatric aspects of delirium. Yudofsky S, Hales R, eds. American psychiatric association textbook of neuropsychiatry. 5th edn. Washington DC: American Psychiatric Publishing, 2007.

48 Trzepacz PT, Mittal D, Torres R, et al. Validation of the delirium rating Scale-revised-98: comparison with the delirium rating scale and the cognitive test for delirium. J Neuropsychiatry Clin Neurosci 2001;13:229-42.

49 Agresti A. Categorical data analysis. Hoboken, NJ: John Wiley and Sons, Inc, 2003.

50 Gustafson Y, Olsson T, Eriksson S, et al. Acute confusional states (delirium) in stroke patients. Cerebrovasc Dis 1991;1:257-64. 